\title{
Malaria vaccines: identifying Plasmodium falciparum liver-stage targets
}

\author{
Rhea J. Longley *t, Adrian V. S. Hill and Alexandra J. Spencer \\ The Jenner Institute, Nuffield Department of Medicine, University of Oxford, Oxford, UK
}

OPEN ACCESS

Edited by:

Ute Frevert,

New York University School of Medicine, USA

Reviewed by:

Ann-Kristin Mueller

University Hospital Heidelberg,

Germany

Alberto Moreno,

Emory University, USA

*Correspondence:

Rhea J. Longley,

The Jenner Institute, Nuffield

Department of Medicine, University

of Oxford, Oxford, UK

longley.r@wehi.edu.au

tPresent address:

Rhea J. Longley,

The Walter and Eliza Hall Institute of

Medical Research, Parkville, VIC,

Australia;

Mahidol Vivax Research Unit, Faculty

of Tropical Medicine, Mahidol

University, Bangkok, Thailand;

Department of Medical Biology,

University of Melbourne, Parkville,

VIC, Australia

Specialty section:

This article was submitted to

Microbial Immunology,

a section of the journal

Frontiers in Microbiology

Received: 09 July 2015

Accepted: 31 August 2015

Published: 15 September 2015

Citation:

Longley RJ, Hill AVS and Spencer AJ (2015) Malaria vaccines: identifying

Plasmodium falciparum liver-stage targets. Front. Microbiol. 6:965. doi: 10.3389/fmicb.2015.00965
The development of a highly efficacious and durable vaccine for malaria remains a top priority for global health researchers. Despite the huge rise in recognition of malaria as a global health problem and the concurrent rise in funding over the past 10-15 years, malaria continues to remain a widespread burden. The evidence of increasing resistance to anti-malarial drugs and insecticides is a growing concern. Hence, an efficacious and durable preventative vaccine for malaria is urgently needed. Vaccines are one of the most cost-effective tools and have successfully been used in the prevention and control of many diseases, however, the development of a vaccine for the Plasmodium parasite has proved difficult. Given the early success of whole sporozoite mosquito-bite delivered vaccination strategies, we know that a vaccine for malaria is an achievable goal, with sub-unit vaccines holding great promise as they are simple and cheap to both manufacture and deploy. However a major difficulty in development of sub-unit vaccines lies within choosing the appropriate antigenic target from the 5000 or so genes expressed by the parasite. Given the liver-stage of malaria represents a bottle-neck in the parasite's life cycle, there is widespread agreement that a multi-component sub-unit malaria vaccine should preferably contain a liver-stage target. In this article we review progress in identifying and screening Plasmodium falciparum liver-stage targets for use in a malaria vaccine.

Keywords: malaria, vaccine, liver-stage, T cells, immunity

\section{Introduction}

Malaria is a disease caused by the parasite Plasmodium, of which five species are known to infect humans, and is transmitted by the bite of female Anopheles mosquitoes. In 2013, approximately 584000 people died from malaria (WHO, 2014), the majority due to Plasmodium falciparum. There has been substantial success in reducing mortality rates by approximately $50 \%$ over the past 15 years (WHO, 2014), but there is still a considerable burden of disease and some worrying trends in resistance to anti-malarial drugs. There are increasing reports of resistance to artemisinin in several countries of South East Asia (Ashley et al., 2014), and in addition reports of insecticide resistance to pyrethroids, the only insecticide class licensed for use in impregnated bed-nets, have started to emerge (Ranson et al., 2011). Together, these issues highlight the importance, and potential reliance the global community may have, on developing a highly efficacious and durable vaccine for malaria.

An effective whole parasite vaccination approach for malaria was developed in the early 1970s (Clyde et al., 1973; Rieckmann et al., 1974), building on previous work in animal models 
(Russell and Mohan, 1942; Nussenzweig et al., 1967). The parasite has a complex life cycle; within the human host, sporozoites injected by mosquitoes first travel to the liver. Here they develop for approximately 7 days, before entering into the bloodstream. The blood-stage is responsible for all symptoms associated with malaria, and gives rise to the sexual forms known as gametocytes. Researchers were able to demonstrate sterile protection - the complete absence of blood-stage parasites - after administration of irradiated sporozoites by mosquito bites. These irradiated sporozoites are able to invade the liver but development is arrested, providing a repertoire of antigens for the immune system to recognize without the host experiencing a blood-stage infection. Whilst this vaccination strategy was highly efficacious, it had numerous logistical issues, including the need to receive over 1000 bites from mosquitoes. Now, the biotechnology company Sanaria can cryopreserve sporozoites and vaccinate by needle-and-syringe, resulting in high levels of protection against subsequent challenge if 4-5 intravenous doses are administered (Seder et al., 2013), however, the durability of protection from this formulation has not yet been published. In addition, a number of manufacturing and logistical issues still remain, such as cost of manufacture, the route of administration, the need for storage in liquid nitrogen vapor phase and the requirement for large numbers of doses. An alternate, likely more practical, approach is sub-unit vaccination.

To-date, the most successful sub-unit vaccine is RTS,S Greenwood (2015), a particulate vaccine directed at the circumsporozoite protein (CSP). CSP is the major coat protein on the sporozoite surface (Yoshida et al., 1980; Nussenzweig and Nussenzweig, 1985) and is implicated in protection mediated by irradiated sporozoites (Gwadz et al., 1979; Nardin et al., 1982). The Phase III trial of RTS,S/AS01 conducted at eleven sites within seven African countries demonstrated 28\% efficacy for 5-17 month-old children and 18\% efficacy for 6-12 week-old infants with three doses, over the entire course of the study $(\sim 3-$ 4 years of follow-up; Greenwood, 2015). Our group has also had some success with a virally vectored sub-unit vaccine directed at the pre-erythrocytic antigen thrombospondin-related adhesion protein (TRAP) fused to a multi-epitope (ME) string (Gilbert et al., 1997; McConkey et al., 2003). When delivered in the vectors chimpanzee adenovirus 63 (ChAd63) and modified vaccinia virus Ankara (MVA), ME-TRAP provided $21 \%$ sterile protection in malaria-naïve adults, associated with $\mathrm{CD}^{+} \mathrm{T}$ cells inducing IFN- $\gamma$ (Ewer et al., 2013). In the first field trial of this approach, significant efficacy (67\%) in preventing PCR-detectable parasites was observed in Kenyan adults (Ogwang et al., 2015). Subunit vaccines with antigenic targets from the blood-stage of infection are also in clinical development (Drew and Beeson, 2015).

Given neither TRAP nor CSP alone (nor any blood-stage candidate) can match the protection induced by irradiated sporozoites, it is likely that a broad immune response to multiple target antigens will contribute to improved sub-unit vaccine efficacy. Only a minority of potential candidate antigens have been assessed as vaccine candidates, and CSP and TRAP may not be the best targets (Doolan et al., 2003; Kumar et al., 2006; Trieu et al., 2011). Furthermore, including multiple antigenic targets in one vaccine might overcome limitations in genetically restricted responses to certain epitopes (Doolan et al., 1996). The difficulty is choosing which antigenic targets from the 5000 or so genes expressed by the parasite (Gardner et al., 2002) should be incorporated. There is widespread agreement that a liver-stage target would be a desirable addition to a multi-component subunit malaria vaccine targeting another life-cycle stage, given that it represents a bottle-neck in the parasite's life-cycle and could also be transmission blocking, by preventing development to the blood-stage and hence the formation of gametocytes.

In this article we therefore review what has been learnt so far in terms of identification and screening of novel liver-stage vaccine targets.

\section{Identifying Liver-Stage Targets}

The discovery of the Plasmodium genome (Gardner et al., 2002) and proteome (Florens et al., 2002) has yielded a huge number of potential liver-stage targets, but has not necessarily provided information as to which should or could be included in a vaccine. In this section we will discuss a number of methods that could be used to prioritize antigens.

\section{Transcriptomic Profiling}

Transcriptomic profiling of the $P$. falciparum liver-stage would uncover genes that are actively being expressed. This has, however, not been a simple task to undertake, even in murine models, given the high proportion of uninfected hepatocytes (Lau et al., 2001). Nevertheless, using techniques such as laser capture microdissection, axenically cultured exo-erythrocytic forms and fluorescent parasites, the $P$. yoelii transcriptome has been described, with around 1000 proteins likely expressed at the liver-stage (Wang et al., 2004; Sacci et al., 2005; Tarun et al., 2008). The $P$. yoelii liver-stage lasts for only 2 days, compared to 7 days for $P$. falciparum, and hence there are likely important differences in the transcriptomic profiles of these species. For example, the $P$. falciparum liver-stage specific protein liver-stage antigen 1 (LSA1) does not have a murine ortholog but is critical for late-liver-stage development (Mikolajczak et al., 2011).

Only one published study to our knowledge has attempted to define the $P$. falciparum liver-stage specific transcriptome. Siau et al. (2008) found 532 genes up-regulated following co-culture of $P$. falciparum sporozoites and primary human hepatocytes in vitro when compared to genes expressed in sporozoites alone. We recently demonstrated sterile protection following vaccination with one candidate identified in this study, liverstage associated protein 2 (LSAP2; Longley et al., 2015b). This transcriptomic study was designed to identify genes important in the invasive period of the liver-stage, and hence they co-cultured the sporozoites and hepatocytes for only $1 \mathrm{~h}$. Further research is now needed to determine the complete transcriptome, including late liver-stage development.

\section{Epitope Identification}

To be immunogenic and targeted by $\mathrm{T}$ cells, the proteins need to be processed and epitopes presented on the hepatocyte cell 
surface in association with the major histocompatibility complex (MHC). Identifying which epitopes are presented at the liverstage is hence also a rational method of choosing functionally important antigens. One method of epitope identification is prediction software (Trolle et al., 2015), used to predict the MHC binding capacity. This method has been applied to $P$. falciparum (Doolan et al., 2003) and reviewed in detail (Doolan, 2011) so will not be discussed further here, except to note that these predictions were made using the sporozoite proteome and that once the liver-stage specific P. falciparum proteome is known, they should be revisited. The risk with epitope prediction software is the rate of false positive identification (Zhong et al., 2003).

A direct method of epitope identification is the elution of peptides from P. falciparum infected hepatocytes. Generally, MHC-peptide complexes are isolated, the peptides eluted and separated by mass spectrometry, and subsequently sequenced (Hunt et al., 1992). This methodology has been used to identify epitopes for influenza (Testa et al., 2012), hepatitis C (Wolk et al., 2012), ovarian cancer (Ramakrishna et al., 2003), and tuberculosis (Flyer et al., 2002), but to our knowledge has not yet been used for P. falciparum due to the constraints on access to and infectability of hepatocytes.

Another method of epitope identification is a proprietary approach developed by Genocea Biosciences, Inc., known as ATLAS $^{\text {TM }}$. They created a 'high throughput, proteomic technology that facilitates unbiased and comprehensive identification of both $\mathrm{CD}^{+}$and $\mathrm{CD}^{+}{ }^{+} \mathrm{T}$ cell antigens' (Long et al., 2014). The rationale is to use whole proteins, rather than peptides, to stimulate immune cells from large numbers of individuals from two groups, those naturally protected from the pathogen and those susceptible. By developing a high-throughput technology able to screen large numbers of individuals they reduce the effect of HLA-restrictions. Furthermore, utilizing whole proteins, which are then processed by each volunteer's own APCs, the resultant epitopes should be unbiased. This methodology is currently being explored for the identification of $P$. falciparum T cell targets.

\section{Source of Hepatocytes}

The major limitations for both transcriptomic profiling and epitope identification are the source of infected hepatocytes and an absence of a perfect model of $P$. falciparum liverstage infection. Whilst both hepatoma cell lines and primary human hepatocytes can be infected with $P$. falciparum in vitro, the infectivity rates are very low $(\sim 0.1 \%$; Mazier et al., 1985 ; Sattabongkot et al., 2006; March et al., 2013). In addition, $P$. falciparum sporozoites cannot naturally infect small rodents. Murine Plasmodium species are commonly used to study the liver-stage of infection in mice and in vitro, yet it is not clear how well these models reflect $P$. falciparum infections in humans. Whilst non-human primates can be infected with adapted human malaria parasites, they are not widely available and cost and ethical considerations of studies on higher order species are limiting factors.

An alternative model is the use of humanized mice; a number of laboratories now routinely infect various models of humanized mice with P. falciparum parasites (Morosan et al., 2006; Sacci et al., 2006; Vaughan et al., 2012b), after repopulation of 80$90 \%$ of the liver with human hepatocytes. The advantages over an in vitro model are that larger liver-stage parasites develop, up to $80 \mu \mathrm{m}$ compared to $15-40 \mu \mathrm{m}$ in culture (Mazier et al., 1985; Sattabongkot et al., 2006; Vaughan et al., 2012b). The larger size is more similar to results from studies of human infections (Shortt et al., 1951; Jeffery et al., 1952). Furthermore, liver-stage artifacts or abortive forms of parasites are often detected in cultures, yet this has not been observed in humanized mice. Whilst there are a number of disadvantages to this model (especially cost), it may be the most practical for obtaining large numbers of infected hepatocytes for antigen identification.

\section{Human Whole Sporozoite Immmunization for Antigen Identification}

Once potential antigens or epitopes have been prioritized, cells from irradiated sporozoite immunization studies can be utilized to confirm that down-selected target antigens are immunogenic in vaccinated volunteers and to try and identify protective antigens. This is possible as protection in irradiated sporozoite vaccination models is dependent on $\mathrm{T}$ cells targeting the liverstage (Schofield et al., 1987; Weiss et al., 1988; Hoffman et al., 1989; Seguin et al., 1994; Weiss and Jiang, 2012). Doolan et al. (2003) adopted this method to attempt to validate their antigens identified using epitope prediction software.

Alternatively, immunity can now be induced in humans with cryopreserved sporozoites (Sanaria ${ }^{\circledR} \mathrm{PfSPZ}-\mathrm{CVac}$ ) or mosquito bite delivered sporozoites under drug cover (Roestenberg et al., 2011; Bijker et al., 2013). A major difficulty with this general approach is that of statistical power. With whole sporozoite strategies only tens of subjects are generally immunized and challenged and it is difficult to quantify degrees of protection precisely in each individual. Because there are hundreds of possible liver-stage antigens to be assayed, and most people respond weakly to most antigens, it is likely to be difficult to pinpoint the best individual protective antigen(s) standing out above the level of efficacy provided by the cumulative effects of large numbers of other antigens.

Unfortunately, this is also a limitation for the ATLAS $^{\text {TM }}$ technology, as it relies on access to cells from humans whom are protected by whole pathogen exposure: for other pathogens they have used cells from exposed individuals (Long et al., 2014), whereas for malaria naturally exposed or challenged individuals generally have weak $\mathrm{T}$ cell responses (Offeddu et al., 2012; Sheehy et al., 2013). Hence, immunization models, such as described below, may be more useful.

\section{Screening Targets}

Once candidate antigens have been identified, a functional assay to assess pre-clinical efficacy needs to be employed. The challenges are twofold: $P$. falciparum does not infect small animals, and there is no standardized in vitro assay to measure $\mathrm{T}$ cell killing of liver-stage parasites. 


\section{Mouse Models}

In the past, candidate antigens have been screened in mice using $P$. berghei or $P$. yoelii orthologs of the P. falciparum antigen of interest. It is still unclear how well these results translate to human trials, and importantly, not all $P$. falciparum antigens have murine orthologs. Alternate options are the use of transgenic parasites and humanized mice.

Transgenic parasites are a powerful tool that can enable functional screening of $P$. falciparum (or $P$. vivax) vaccine efficacy in mice (Persson et al., 2002; Mlambo et al., 2008; Cao et al., 2009; Espinosa et al., 2013; Porter et al., 2013; Bauza et al., 2014; Deal et al., 2014; Mizutani et al., 2014; Schwenk et al., 2014). Two methods are commonly used: (1) replacement of the endogenous $P$. berghei (or $P$. yoelii) gene with the P. falciparum ortholog under control of the relevant $P$. berghei promoter, or (2) addition of the P. falciparum copy of the gene inserted at a different and dispensable point in the genome (required when no murine ortholog exists). For example, the $230 p$ locus in both $P$. berghei and $P$. yoelii is considered "silent", and replacement of this gene has no adverse effect on expression of other genes and no impact on parasite viability or behavior (Janse et al., 2006; van Dijk et al., 2010; Lin et al., 2011). We have recently used this method of screening to identify PfLSA1 and PfLSAP2 as potential candidates for a liver-stage malaria vaccine (Longley et al., 2015b): we were able to screen ten antigens for homologous efficacy in mice, and both PfLSA1 and PfLSAP2 outperformed CSP and TRAP in this model. We were also able to utilize the transgenic parasites to demonstrate that efficacy was primarily dependent on $\mathrm{CD}^{+} \mathrm{T}$ cells.

The main limitation of the addition rather than replacement technique is that the P. falciparum transgene is under control of a non-native promoter, potentially leading to differential patterns of gene expression. In addition, for both the replacement and addition strategies experiments are still undertaken in mice and the limited MHC system favors immunodominant responses, although this can be mitigated if outbred mice are studied. It is important to note that this is an artificial model system, and only once clinical trials of candidates selected in this manner have been undertaken successfully will we know its true value.

An alternative option is the use of humanized mice permissible to $P$. falciparum infection. As these mice are immunodeficient (Morosan et al., 2006; Sacci et al., 2006; Vaughan et al., 2012b) they would not be suitable for vaccination, but $\mathrm{T}$ cells from classical inbred mice could be adoptively transferred. To our knowledge this option has not yet been explored, but warrants some attention and preliminary experimentation to determine the feasibility.

\section{In Vitro Assays}

In vitro assays could also be used for screening liver-stage vaccine candidates. P. falciparum-infected primary human hepatocytes and hepatoma cell lines have been used to measure antibody inhibition of invasion and growth (Mazier et al., 1986; Hollingdale et al., 1987, 1990; Mellouk et al., 1990; Fidock et al., 1997; Brahimi et al., 2001; House et al., 2009; Zou et al., 2013; Finney et al., 2014). To-date, only murine Plasmodium infected hepatocytes have been used to measure T cell-mediated protection (Hoffman et al., 1989; Weiss et al., 1990; Renia et al., 1991, 1993; Trimnell et al., 2009). T-cell assays require MHC effector-target cell matching, complicating the assay, and perhaps explaining in part why it has received little attention for many years. We have since revisited this assay, incorporating a number of technological advances such as fluorescent parasites to simplify the assay design and interpretation (Longley et al., 2015a). We utilized $P$. berghei TRAP as a model antigen and demonstrated TRAP-specific $\mathrm{CD}^{+} \mathrm{T}$ cell enriched splenocytes were able to inhibit $P$. berghei infected hepatoma cells in an effector-to-target ratio dependent manner.

However, the assessment of inhibition of P. falciparum infected human hepatocytes or hepatoma cell lines by human $\mathrm{T}$ cells is still an elusive goal. The difficulties are fourfold: (1) the rate of infectivity of $P$. falciparum sporozoites into human hepatocytes or hepatoma cells is inherently lower than that of murine Plasmodium species (Mazier et al., 1985; Sattabongkot et al., 2006); (2) P. falciparum sporozoites are more difficult to produce in the laboratory than murine species; (3) the lack of a $P$. falciparum parasite line with strong expression of a fluorescent or other visual marker throughout the entire lifecycle; and (4) the limited choice of human hepatoma cell lines with different HLA types (Karnasuta et al., 1995; Sattabongkot et al., 2006). Yet these barriers are constantly being reduced with improvements to liver-stage culture techniques (March et al., 2013; Zou et al., 2013; Ng et al., 2014) and the availability of cryopreserved $P$. falciparum parasites that could also reduce variability between assays (Sheehy et al., 2013). In addition, new P. falciparum parasites expressing fluorescent or luminescent markers are becoming available (Talman et al., 2010; Vaughan et al., 2012a), and flow cytometry detection of $P$. falciparum infected human hepatocytes and hepatoma cells has recently been demonstrated (Dumoulin et al., 2015). Finally the availability of cryopreserved primary human hepatocytes enriches the HLA-repertoire of target cells available (Li, 2014).

The remaining hurdle is the source of vaccine-induced human $\mathrm{T}$ cells. One option is through vaccination of human volunteers in clinical trials, however, this is not amenable to screening a large number of candidate antigens/vaccines. An alternate option is stimulation of naïve $\mathrm{T}$ cells in vitro (Gaucher et al., 2008), or alternatively (re-)stimulation of malaria-exposed T cells (for instance, sourced from whole sporozoite immunization studies, as described above).

The main advantage of using an in vitro system over in vivo murine models is the limited MHC repertoire of mice. Vaccination in mice often induces a response to only one immunodominant epitope; in humans, there are multiple epitopes that are often different between vaccinated individuals. However, as mentioned above, this can be overcome using outbred mice, although this still does not reflect the HLAtypes of a human population. In turn, the in vitro model is still an artificial system, and likely does not recapitulate all immunological processes (such as signaling pathways) that would occur in vivo. Ultimately, screening liver-stage targets in both models (in vivo and in vitro) would be preferential. 


\section{Immune Correlates of Protection}

Ideally, these methods would not only provide a useful model for screening liver-stage vaccine candidates, but also be used to define correlates of protection. If any of the functional assays of immunity described above (in vivo or in vitro) could accurately predict which vaccines provided protection in CHMI trials, the assay could then be used as a surrogate for protection. This could potentially alleviate the need for very large and expensive CHMI trials at the initial stages of vaccine assessment and would be extremely beneficial for the development of second-generation malaria vaccines.

\section{Summary and Conclusion}

In summary, in the current absence of a deployable and highly efficacious malaria vaccine, significant advances are enabling the identification of new $P$. falciparum liver-stage vaccine targets. Various antigen identification platforms are helping to reduce the number of potential candidates, and simultaneously, methods to screen such candidates are greatly improving. It will be of great interest to see whether any recently identified candidates,

\section{References}

Ashley, E. A., Dhorda, M., Fairhurst, R. M., Amaratunga, C., Lim, P., Suon, S., et al. (2014). Spread of artemisinin resistance in Plasmodium falciparum malaria. N. Engl. J. Med. 371, 411-423. doi: 10.1056/NEJMoa1314981

Bauza, K., Malinauskas, T., Pfander, C., Anar, B., Jones, E. Y., Billker, O., et al. (2014). Efficacy of a Plasmodium vivax malaria vaccine using ChAd63 and modified vaccinia Ankara expressing thrombospondin-related anonymous protein as assessed with transgenic Plasmodium berghei parasites. Infect. Immun. 82, 1277-1286. doi: 10.1128/iai.01187-1113

Bijker, E. M., Bastiaens, G. J., Teirlinck, A. C., Van Gemert, G. J., Graumans, W., Van De Vegte-Bolmer, M., et al. (2013). Protection against malaria after immunization by chloroquine prophylaxis and sporozoites is mediated by preerythrocytic immunity. Proc. Natl. Acad. Sci. U.S.A. 110, 7862-7867. doi: 10.1073/pnas.1220360110

Brahimi, K., Badell, E., Sauzet, J. P., Benmohamed, L., Daubersies, P., GuerinMarchand, C., et al. (2001). Human antibodies against Plasmodium falciparum liver-stage antigen 3 cross-react with Plasmodium yoelii preerythrocytic-stage epitopes and inhibit sporozoite invasion in vitro and in vivo. Infect. Immun. 69, 3845-3852. doi: 10.1128/iai.69.6.3845-3952.2001

Cao, Y., Zhang, D., and Pan, W. (2009). Construction of transgenic Plasmodium berghei as a model for evaluation of blood-stage vaccine candidate of Plasmodium falciparum chimeric protein 2.9. PLoS ONE 4:e6894. doi: 10.1371/journal.pone.0006894

Clyde, D. F., Most, H., Mccarthy, V. C., and Vanderberg, J. P. (1973). Immunization of man against sporozite-induced falciparum malaria. Am. J. Med. Sci. 266, 169-177. doi: 10.1097/00000441-19730900000002

Deal, C., Balazs, A. B., Espinosa, D. A., Zavala, F., Baltimore, D., and Ketner, G. (2014). Vectored antibody gene delivery protects against Plasmodium falciparum sporozoite challenge in mice. Proc. Natl. Acad. Sci. U.S.A. 111, 12528-12532. doi: 10.1073/pnas.1407362111

Dembele, L., Franetich, J. F., Lorthiois, A., Gego, A., Zeeman, A. M., Kocken, C. H., et al. (2014). Persistence and activation of malaria hypnozoites in long-term primary hepatocyte cultures. Nat. Med. 20, 307-312. doi: 10.1038/nm.3461

Doolan, D. L. (2011). Plasmodium immunomics. Int. J. Parasitol. 41, 3-20. doi: 10.1016/j.ijpara.2010.08.002

Doolan, D. L., Sedegah, M., Hedstrom, R. C., Hobart, P., Charoenvit, Y., and Hoffman, S. L. (1996). Circumventing genetic restriction of protection such as PfLSAP2, translate into protective efficacy in CHMI trials of non-immune adults. We believe these new identification and screening platforms will greatly enhance the development of second-generation malaria vaccines. In addition, it is also acknowledged that control and elimination of $P$. vivax, the most widespread of the Plasmodium sp. causing human disease, would be accelerated by the development of a $P$. vivax vaccine. Whilst this species has not been considered in this review, it is important to note that recent developments of novel tools to study $P$. vivax liver-stage biology, such as infection and generation of $P$. vivax dormant liver-stage forms both in humanized mice (Mikolajczak et al., 2015) and in vitro (Dembele et al., 2014), will be of great use in identifying $P$. vivax liver-stage targets in the future.

\section{Funding}

RL was supported by the Rhodes Trust and a Nuffield Department of Medicine Studentship; AH is a Jenner Institute Investigator and a Wellcome Trust and NIHR Senior Investigator; AS is a James Martin Fellow.

against malaria with multigene DNA immunization: CD8+ cell-, interferon gamma-, and nitric oxide-dependent immunity. J. Exp. Med. 183, 1739-1746. doi: 10.1084/jem.183.4.1739

Doolan, D. L., Southwood, S., Freilich, D. A., Sidney, J., Graber, N. L., Shatney, L., et al. (2003). Identification of Plasmodium falciparum antigens by antigenic analysis of genomic and proteomic data. Proc. Natl. Acad. Sci. U.S.A. 100, 9952-9957. doi: 10.1073/pnas.1633254100

Drew, D. R., and Beeson, J. G. (2015). PfRH5 as a candidate vaccine for Plasmodium falciparum malaria. Trends Parasitol. 31, 87-88. doi: 10.1016/j.pt.2015.02.001

Dumoulin, P. C., Trop, S. A., Ma, J., Zhang, H., Sherman, M. A., and Levitskaya, J. (2015). Flow cytometry based detection and isolation of Plasmodium falciparum liver stages in vitro. PLoS ONE 10:e0129623. doi: 10.1371/journal.pone.0129623

Espinosa, D. A., Yadava, A., Angov, E., Maurizio, P. L., Ockenhouse, C. F., and Zavala, F. (2013). Development of a chimeric Plasmodium berghei strain expressing the repeat region of the $P$. vivax circumsporozoite protein for in vivo evaluation of vaccine efficacy. Infect. Immun. 81, 2882-2887. doi: 10.1128/iai.00461-413

Ewer, K. J., O’hara, G. A., Duncan, C. J., Collins, K. A., Sheehy, S. H., ReyesSandoval, A., et al. (2013). Protective CD8 ${ }^{+}$T-cell immunity to human malaria induced by chimpanzee adenovirus-MVA immunisation. Nat. Commun. 4, 2836. doi: 10.1038/ncomms3836

Fidock, D. A., Pasquetto, V., Gras, H., Badell, E., Eling, W., Ballou, W. R., et al. (1997). Plasmodium falciparum sporozoite invasion is inhibited by naturally acquired or experimentally induced polyclonal antibodies to the STARP antigen. Eur. J. Immunol. 27, 2502-2513. doi: 10.1002/eji.1830271007

Finney, O. C., Keitany, G. J., Smithers, H., Kaushansky, A., Kappe, S., and Wang, R. (2014). Immunization with genetically attenuated $P$. falciparum parasites induces long-lived antibodies that efficiently block hepatocyte invasion by sporozoites. Vaccine 32, 2135-2138. doi: 10.1016/j.vaccine.2014.02.055

Florens, L., Washburn, M. P., Raine, J. D., Anthony, R. M., Grainger, M., Haynes, J. D., et al. (2002). A proteomic view of the Plasmodium falciparum life cycle. Nature 419, 520-526. doi: 10.1038/nature01107

Flyer, D. C., Ramakrishna, V., Miller, C., Myers, H., Mcdaniel, M., Root, K., et al. (2002). Identification by mass spectrometry of $\mathrm{CD}^{+}$-T-cell Mycobacterium tuberculosis epitopes within the Rv0341 gene product. Infect. Immun. 70, 2926-2932. doi: 10.1128/IAI.70.6.2926-2932.2002

Gardner, M. J., Hall, N., Fung, E., White, O., Berriman, M., Hyman, R. W., et al. (2002). Genome sequence of the human malaria parasite Plasmodium falciparum. Nature 419, 498-511. doi: 10.1038/nature01097 
Gaucher, D., Therrien, R., Kettaf, N., Angermann, B. R., Boucher, G., FilaliMouhim, A., et al. (2008). Yellow fever vaccine induces integrated multilineage and polyfunctional immune responses. J. Exp. Med. 205, 3119-3131. doi: 10.1084/jem.20082292

Gilbert, S. C., Plebanski, M., Harris, S. J., Allsopp, C. E., Thomas, R., Layton, G. T., et al. (1997). A protein particle vaccine containing multiple malaria epitopes. Nat. Biotechnol. 15, 1280-1284. doi: 10.1038/nbt1197-1280

Greenwood, B. M. (2015). Efficacy and safety of RTS,S/AS01 malaria vaccine with or without a booster dose in infants and children in Africa: final results of a phase 3, individually randomised, controlled trial. Lancet 386, 31-45. doi: 10.1016/s0140-6736(15)60721-60728

Gwadz, R. W., Cochrane, A. H., Nussenzweig, V., and Nussenzweig, R. S. (1979). Preliminary studies on vaccination of rhesus monkeys with irradiated sporozoites of Plasmodium knowlesi and characterization of surface antigens of these parasites. Bull. World Health Organ. 57(Suppl. 1), 165-173.

Hoffman, S. L., Isenbarger, D., Long, G. W., Sedegah, M., Szarfman, A., Waters, L., et al. (1989). Sporozoite vaccine induces genetically restricted T cell elimination of malaria from hepatocytes. Science 244, 1078-1081. doi: $10.1126 /$ science. 2524877

Hollingdale, M. R., Appiah, A., Leland, P., Do Rosario, V. E., Mazier, D., Pied, S., et al. (1990). Activity of human volunteer sera to candidate Plasmodium falciparum circumsporozoite protein vaccines in the inhibition of sporozoite invasion assay of human hepatoma cells and hepatocytes. Trans. R. Soc. Trop. Med. Hyg. 84, 325-329. doi: 10.1016/0035-9203(90)90303-V

Hollingdale, M. R., Ballou, W. R., Aley, S. B., Young, J. F., Pancake, S., Miller, L. H., et al. (1987). Plasmodium falciparum: elicitation by peptides and recombinant circumsporozoite proteins of circulating mouse antibodies inhibiting sporozoite invasion of hepatoma cells. Exp. Parasitol. 63, 345-351. doi: 10.1016/0014-4894(87)90182-2

House, B. L., Hollingdale, M. R., Sacci, J. B. Jr., and Richie, T. L. (2009). Functional immunoassays using an in-vitro malaria liver-stage infection model: where do we go from here? Trends Parasitol. 25, 525-533. doi: 10.1016/j.pt.2009.08.004

Hunt, D. F., Henderson, R. A., Shabanowitz, J., Sakaguchi, K., Michel, H., Sevilir, N., et al. (1992). Characterization of peptides bound to the class I MHC molecule HLA-A2.1 by mass spectrometry. Science 255, 1261-1263. doi: 10.1126/science. 1546328

Janse, C. J., Franke-Fayard, B., Mair, G. R., Ramesar, J., Thiel, C., Engelmann, S., et al. (2006). High efficiency transfection of Plasmodium berghei facilitates novel selection procedures. Mol. Biochem. Parasitol. 145, 60-70. doi: 10.1016/j.molbiopara.2005.09.007

Jeffery, G. M., Wolcott, G. B., Young, M. D., and Williams, D. Jr. (1952). Exoerythrocytic stages of Plasmodium falciparum. Am. J. Trop. Med. Hyg. 1, 917-925.

Karnasuta, C., Pavanand, K., Chantakulkij, S., Luttiwongsakorn, N., Rassamesoraj, M., Laohathai, K., et al. (1995). Complete development of the liver stage of Plasmodium falciparum in a human hepatoma cell line. Am. J. Trop. Med. Hyg. 53, 607-611.

Kumar, K. A., Sano, G., Boscardin, S., Nussenzweig, R. S., Nussenzweig, M. C., Zavala, F., et al. (2006). The circumsporozoite protein is an immunodominant protective antigen in irradiated sporozoites. Nature 444, 937-940. doi: 10.1038 /nature05361

Lau, A. O., Sacci, J. B. Jr., and Azad, A. F. (2001). Detection of Plasmodium yoelii stage mRNA in BALB/c mice. J. Parasitol. 87, 19-23. doi: 10.1645/00223395(2001)087[0019:dopysm]2.0.co;2

Li, A. P. (2014). In vitro human hepatocyte-based experimental systems for the evaluation of human drug metabolism, drug-drug interactions, and drug toxicity in drug development. Curr. Top. Med. Chem. 14, 1325-1338. doi: 10.2174/1568026614666140506114411

Lin, J. W., Annoura, T., Sajid, M., Chevalley-Maurel, S., Ramesar, J., Klop, O., et al. (2011). A novel 'gene insertion/marker out' (GIMO) method for transgene expression and gene complementation in rodent malaria parasites. PLoS ONE 6:e29289. doi: 10.1371/journal.pone.0029289

Long, D., Skoberne, M., Gierahn, T. M., Larson, S., Price, J. A., Clemens, V., et al. (2014). Identification of novel virus-specific antigens by $\mathrm{CD} 4^{+}$and $\mathrm{CD} 8^{+} \mathrm{T}$ cells from asymptomatic HSV-2 seropositive and seronegative donors. Virology 464-465, 296-311. doi: 10.1016/j.virol.2014.07.018

Longley, R. J., Bauza, K., Ewer, K. J., Hill, A. V., and Spencer, A. J. (2015a). Development of an in vitro assay and demonstration of Plasmodium berghei liver-stage inhibition by TRAP-specific $\mathrm{CD}^{+}{ }^{+}$T cells. PLoS ONE 10:e0119880. doi: 10.1371/journal.pone.0119880

Longley, R. J., Salman, A. M., Cottingham, M. G., Ewer, K., Janse, C. J., Khan, S. M., et al. (2015b). Comparative assessment of vaccine vectors encoding ten malaria antigens identifies two protective liver-stage candidates. Sci. Rep. 5, 11820. doi: 10.1038/srep11820

March, S., Ng, S., Velmurugan, S., Galstian, A., Shan, J., Logan, D. J., et al. (2013). A microscale human liver platform that supports the hepatic stages of Plasmodium falciparum and vivax. Cell Host Microbe 14, 104-115. doi: 10.1016/j.chom.2013.06.005

Mazier, D., Beaudoin, R. L., Mellouk, S., Druilhe, P., Texier, B., Trosper, J., et al. (1985). Complete development of hepatic stages of Plasmodium falciparum in vitro. Science 227, 440-442. doi: 10.1126/science.3880923

Mazier, D., Mellouk, S., Beaudoin, R. L., Texier, B., Druilhe, P., Hockmeyer, W., et al. (1986). Effect of antibodies to recombinant and synthetic peptides on $P$. falciparum sporozoites in vitro. Science 231, 156-159. doi: 10.1126/science. 3510455

McConkey, S. J., Reece, W. H., Moorthy, V. S., Webster, D., Dunachie, S., Butcher, G., et al. (2003). Enhanced T-cell immunogenicity of plasmid DNA vaccines boosted by recombinant modified vaccinia virus Ankara in humans. Nat. Med. 9, 729-735. doi: 10.1038/nm881

Mellouk, S., Berbiguier, N., Druilhe, P., Sedegah, M., Galey, B., Yuan, L., et al. (1990). Evaluation of an in vitro assay aimed at measuring protective antibodies against sporozoites. Bull. World Health Organ. 68(Suppl.), 52-59.

Mikolajczak, S. A., Sacci, J. B. Jr., De La Vega, P., Camargo, N., Vanbuskirk, K., Krzych, U., et al. (2011). Disruption of the Plasmodium falciparum liver-stage antigen-1 locus causes a differentiation defect in late liver-stage parasites. Cell Microbiol. 13, 1250-1260. doi: 10.1111/j.1462-5822.2011.01617.x

Mikolajczak, S. A., Vaughan, A. M., Kangwanrangsan, N., Roobsoong, W., Fishbaugher, M., Yimamnuaychok, N., et al. (2015). Plasmodium vivax liver stage development and hypnozoite persistence in human liverchimeric mice. Cell Host Microbe 17, 526-535. doi: 10.1016/j.chom.2015. 02.011

Mizutani, M., Iyori, M., Blagborough, A. M., Fukumoto, S., Funatsu, T., Sinden, R. E., et al. (2014). Baculovirus-vectored multistage Plasmodium vivax vaccine induces both protective and transmission-blocking immunities against transgenic rodent malaria parasites. Infect. Immun. 82, 4348-4357. doi: 10.1128/iai.02040-2014

Mlambo, G., Maciel, J., and Kumar, N. (2008). Murine model for assessment of Plasmodium falciparum transmission-blocking vaccine using transgenic Plasmodium berghei parasites expressing the target antigen Pfs 25 . Infect. Immun. 76, 2018-2024. doi: 10.1128/iai.01409-1407

Morosan, S., Hez-Deroubaix, S., Lunel, F., Renia, L., Giannini, C., Van Rooijen, N., et al. (2006). Liver-stage development of Plasmodium falciparum, in a humanized mouse model. J. Infect. Dis. 193, 996-1004. doi: 10.1086/500840

Nardin, E. H., Nussenzweig, V., Nussenzweig, R. S., Collins, W. E., Harinasuta, K. T., Tapchaisri, P., et al. (1982). Circumsporozoite proteins of human malaria parasites Plasmodium falciparum and Plasmodium vivax. J. Exp. Med. 156, 20-30. doi: 10.1084/jem.156.1.20

Ng, S., March, S., Galstian, A., Hanson, K., Carvalho, T., Mota, M. M., et al. (2014). Hypoxia promotes liver-stage malaria infection in primary human hepatocytes in vitro. Dis. Model. Mech. 7, 215-224. doi: 10.1242/dmm.013490

Nussenzweig, R. S., Vanderberg, J., Most, H., and Orton, C. (1967). Protective immunity produced by the injection of $\mathrm{x}$-irradiated sporozoites of Plasmodium berghei. Nature 216, 160-162. doi: 10.1038/216160a0

Nussenzweig, V., and Nussenzweig, R. S. (1985). Circumsporozoite proteins of malaria parasites. Cell 42, 401-403. doi: 10.1016/0092-8674(85)90093-5

Offeddu, V., Thathy, V., Marsh, K., and Matuschewski, K. (2012). Naturally acquired immune responses against Plasmodium falciparum sporozoites and liver infection. Int. J. Parasitol. 42, 535-548. doi: 10.1016/j.ijpara.2012.03.011

Ogwang, C., Kimani, D., Edwards, N. J., Roberts, R., Mwacharo, J., Bowyer, G., et al. (2015). Prime-boost vaccination with chimpanzee adenovirus and modified vaccinia Ankara encoding TRAP provides partial protection against Plasmodium falciparum infection in Kenyan adults. Sci Trans. Med. 7, 286re285. doi: 10.1126/scitranslmed.aaa2373

Persson, C., Oliveira, G. A., Sultan, A. A., Bhanot, P., Nussenzweig, V., and Nardin, E. (2002). Cutting edge: a new tool to evaluate human preerythrocytic malaria vaccines: rodent parasites bearing a hybrid Plasmodium 
falciparum circumsporozoite protein. J. Immunol. 169, 6681-6685. doi: 10.4049/jimmunol.169.12.6681

Porter, M. D., Nicki, J., Pool, C. D., Debot, M., Illam, R. M., Brando, C., et al. (2013). Transgenic parasites stably expressing full-length Plasmodium falciparum circumsporozoite protein as a model for vaccine down-selection in mice using sterile protection as an endpoint. Clin. Vaccine Immunol. 20, 803-810. doi: 10.1128/cvi.00066-13

Ramakrishna, V., Ross, M. M., Petersson, M., Gatlin, C. C., Lyons, C. E., Miller, C. L., et al. (2003). Naturally occurring peptides associated with HLAA2 in ovarian cancer cell lines identified by mass spectrometry are targets of HLA-A2-restricted cytotoxic T cells. Int. Immunol. 15, 751-763. doi: 10.1093/intimm/dxg074

Ranson, H., N'guessan, R., Lines, J., Moiroux, N., Nkuni, Z., and Corbel, V. (2011). Pyrethroid resistance in African anopheline mosquitoes: what are the implications for malaria control? Trends Parasitol. 27, 91-98. doi: 10.1016/j.pt.2010.08.004

Renia, L., Grillot, D., Marussig, M., Corradin, G., Miltgen, F., Lambert, P. H., et al. (1993). Effector functions of circumsporozoite peptide-primed CD4 ${ }^{+} \mathrm{T}$ cell clones against Plasmodium yoelii liver stages. J. Immunol. 150, 1471-1478.

Renia, L., Marussig, M. S., Grillot, D., Pied, S., Corradin, G., Miltgen, F., et al. (1991). In vitro activity of $\mathrm{CD}^{+}$and $\mathrm{CD}^{+} \mathrm{T}$ lymphocytes from mice immunized with a synthetic malaria peptide. Proc. Natl. Acad. Sci. U.S.A. 88, 7963-7967. doi: 10.1073/pnas.88.18.7963

Rieckmann, K. H., Carson, P. E., Beaudoin, R. L., Cassells, J. S., and Sell, K. W. (1974). Letter: sporozoite induced immunity in man against an Ethiopian strain of Plasmodium falciparum. Trans. R. Soc. Trop Med. Hyg. 68, 258-259. doi: 10.1016/0035-9203(74)90129-1

Roestenberg, M., Teirlinck, A. C., Mccall, M. B., Teelen, K., Makamdop, K. N., Wiersma, J., et al. (2011). Long-term protection against malaria after experimental sporozoite inoculation: an open-label follow-up study. Lancet 377, 1770-1776. doi: 10.1016/s0140-6736(11)60360-60367

Russell, P. F., and Mohan, B. N. (1942). The immunization of fowls against mosquito-borne Plasmodium gallinaceum by injections of serum and of inactivated homologous sporozoites. J. Exp. Med. 76, 477-495. doi: 10.1084/jem.76.5.477

Sacci, J. B. Jr., Alam, U., Douglas, D., Lewis, J., Tyrrell, D. L., Azad, A.F., et al. (2006). Plasmodium falciparum infection and exoerythrocytic development in mice with chimeric human livers. Int. J. Parasitol. 36, 353-360. doi: 10.1016/j.ijpara.2005.10.014

Sacci, J. B. Jr., Ribeiro, J. M., Huang, F., Alam, U., Russell, J. A., Blairet, P. L., et al. (2005). Transcriptional analysis of in vivo Plasmodium yoelii liver stage gene expression. Mol. Biochem. Parasitol. 142, 177-183. doi: 10.1016/j.molbiopara.2005.03.018

Sattabongkot, J., Yimamnuaychoke, N., Leelaudomlipi, S., Rasameesoraj, M., Jenwithisuk, R., Coleman, R. E., et al. (2006). Establishment of a human hepatocyte line that supports in vitro development of the exo-erythrocytic stages of the malaria parasites Plasmodium falciparum and P. vivax. Am. J. Trop. Med. Hyg. 74, 708-715.

Schofield, L., Villaquiran, J., Ferreira, A., Schellekens, H., Nussenzweig, R., and Nussenzweig, V. (1987). Gamma interferon, $\mathrm{CD}^{+} \mathrm{T}$ cells and antibodies required for immunity to malaria sporozoites. Nature 330, 664-666. doi: $10.1038 / 330664 \mathrm{a} 0$

Schwenk, R., Debot, M., Porter, M., Nikki, J., Rein, L., Spaccapelo, R., et al. (2014). IgG2 antibodies against a clinical grade Plasmodium falciparum CSP vaccine antigen associate with protection against transgenic sporozoite challenge in mice. PLoS ONE 9:e111020. doi: 10.1371/journal.pone. 0111020

Seder, R. A., Chang, L. J., Enama, M. E., Zephir, K. L., Sarwar, U. N., Gordon, I. J., et al. (2013). Protection against malaria by intravenous immunization with a nonreplicating sporozoite vaccine. Science 341, 1359-1365. doi: $10.1126 /$ science. 1241800

Seguin, M. C., Klotz, F. W., Schneider, I., Weir, J. P., Goodbary, M., Slayter, M., et al. (1994). Induction of nitric oxide synthase protects against malaria in mice exposed to irradiated Plasmodium berghei infected mosquitoes: involvement of interferon gamma and $\mathrm{CD}^{+} \mathrm{T}$ cells. J. Exp. Med. 180, 353-358. doi: 10.1084/jem.180.1.353

Sheehy, S. H., Spencer, A. J., Douglas, A. D., Sim, B. K., Longley, R. J., Edwards, N. J., et al. (2013). Optimising controlled human malaria infection studies using cryopreserved parasites administered by needle and syringe. PLoS ONE 8:e65960. doi: 10.1371/journal.pone.0065960

Shortt, H. E., Fairley, N. H., Covell, G., Shute, P. G., and Garnham, P. C. (1951). The pre-erythrocytic stage of Plasmodium falciparum. Trans. R. Soc. Trop. Med. Hyg. 44, 405-419. doi: 10.1016/S0035-9203(51)80019-1

Siau, A., Silvie, O., Franetich, J. F., Yalaoui, S., Marinach, C., Hannoun, L., et al. (2008). Temperature shift and host cell contact up-regulate sporozoite expression of Plasmodium falciparum genes involved in hepatocyte infection. PLoS Pathog. 4:e1000121. doi: 10.1371/journal.ppat.10 00121

Talman, A. M., Blagborough, A. M., and Sinden, R. E. (2010). A Plasmodium falciparum strain expressing GFP throughout the parasite's life-cycle. PLoS ONE 5:e9156. doi: 10.1371/journal.pone.0009156

Tarun, A. S., Peng, X., Dumpit, R. F., Ogata, Y., Silva-Rivera, H., Camargo, N., et al. (2008). A combined transcriptome and proteome survey of malaria parasite liver stages. Proc. Natl. Acad. Sci. U.S.A. 105, 305-310. doi: 10.1073/pnas.0710780104

Testa, J. S., Shetty, V., Hafner, J., Nickens, Z., Kamal, S., Sinnathamby, G., et al. (2012). MHC class I-presented T cell epitopes identified by immunoproteomics analysis are targets for a cross reactive influenza-specific T cell response. PLoS ONE 7:e48484. doi: 10.1371/journal.pone.0048484

Trieu, A., Kayala, M. A., Burk, C., Molina, D. M., Freilich, D. A., Richie, T. L., et al. (2011). Sterile protective immunity to malaria is associated with a panel of novel P. falciparum antigens. Mol. Cell Proteomics 10, M111007948. doi: 10.1074/mcp.M111.007948

Trimnell, A., Takagi, A., Gupta, M., Richie, T. L., Kappe, S. H., and Wang, R. (2009). Genetically attenuated parasite vaccines induce contact-dependent CD8 ${ }^{+} \mathrm{T}$ cell killing of Plasmodium yoelii liver stage-infected hepatocytes. J. Immunol. 183, 5870-5878. doi: 10.4049/jimmunol.0900302

Trolle, T., Metushi, I. G., Greenbaum, J. A., Kim, Y., Sidney, J., Lund, O., et al. (2015). Automated benchmarking of peptide-MHC class I binding predictions. Bioinformatics 31, 2174-2181. doi: 10.1093/bioinformatics/ btv123

van Dijk, M. R., Van Schaijk, B. C., Khan, S. M., Van Dooren, M. W., Ramesar, J., Kaczanowski, S., et al. (2010). Three members of the 6-cys protein family of Plasmodium play a role in gamete fertility. PLoS Pathog 6:e1000853. doi: 10.1371/journal.ppat.1000853

Vaughan, A. M., Mikolajczak, S. A., Camargo, N., Lakshmanan, V., Kennedy, M., Lindner, S. E., et al. (2012a). A transgenic Plasmodium falciparum NF54 strain that expresses GFP-luciferase throughout the parasite life cycle. Mol. Biochem. Parasitol. 186, 143-147. doi: 10.1016/j.molbiopara.2012.10.004

Vaughan, A. M., Mikolajczak, S. A., Wilson, E. M., Grompe, M., Kaushansky, A., Camargo, N., et al. (2012b). Complete Plasmodium falciparum liver-stage development in liver-chimeric mice. J. Clin. Invest. 122, 3618-3628. doi: $10.1172 /$ jci62684

Wang, Q., Brown, S., Roos, D. S., Nussenzweig, V., and Bhanot, P. (2004). Transcriptome of axenic liver stages of Plasmodium yoelii. Mol. Biochem. Parasitol. 137, 161-168. doi: 10.1016/j.molbiopara.2004.06.001

Weiss, W. R., and Jiang, C. G. (2012). Protective $\mathrm{CD}^{+}$T lymphocytes in primates immunized with malaria sporozoites. PLOS ONE 7:e31247. doi: 10.1371/journal.pone.0031247

Weiss, W. R., Mellouk, S., Houghten, R. A., Sedegah, M., Kumar, S., Good, M. F., et al. (1990). Cytotoxic T cells recognize a peptide from the circumsporozoite protein on malaria-infected hepatocytes. J. Exp. Med. 171, 763-773. doi: 10.1084/jem.171.3.763

Weiss, W. R., Sedegah, M., Beaudoin, R. L., Miller, L. H., and Good, M. F. (1988). CD8 ${ }^{+} \mathrm{T}$ cells (cytotoxic/suppressors) are required for protection in mice immunized with malaria sporozoites. Proc. Natl. Acad. Sci. U.S.A. 85, 573-576. doi: 10.1073/pnas.85.2.573

WHO. (2014). World Malaria Report 2013. (Geneva: World Health Organization). Wolk, B., Trautwein, C., Buchele, B., Kersting, N., Blum, H. E., Rammensee, H. G., et al. (2012). Identification of naturally processed hepatitis $C$ virus-derived major histocompatibility complex class I ligands. PLOS ONE 7:e29286. doi: 10.1371/journal.pone.0029286

Yoshida, N., Nussenzweig, R. S., Potocnjak, P., Nussenzweig, V., and Aikawa, M. (1980). Hybridoma produces protective antibodies directed against the sporozoite stage of malaria parasite. Science 207, 71-73. doi: $10.1126 /$ science. 6985745 
Zhong, W., Reche, P. A., Lai, C. C., Reinhold, B., and Reinherz, E. L. (2003). Genome-wide characterization of a viral cytotoxic T lymphocyte epitope repertoire. J. Biol. Chem. 278, 45135-45144. doi: 10.1074/jbc.M307417200

Zou, X., House, B. L., Zyzak, M. D., Richie, T. L., and Gerbasi, V. R. (2013). Towards an optimized inhibition of liver stage development assay (ILSDA) for Plasmodium falciparum. Malar. J. 12, 394. doi: 10.1186/1475-2875-12-394

Conflict of Interest Statement: Adrian V. S. Hill is a named investigator on US 12/595 574 and UK PCT/GB2008/01262 novel adenovirus patent applications covering malaria vectored vaccines and immunization regimens; Rhea J. Longley,
Alexandra J. Spencer, and Adrian V. S. Hill are named investigators on filed patent PCT/GB2014/053077 for novel malaria antigens.

Copyright (c) 2015 Longley, Hill and Spencer. This is an open-access article distributed under the terms of the Creative Commons Attribution License (CC BY). The use, distribution or reproduction in other forums is permitted, provided the original author(s) or licensor are credited and that the original publication in this journal is cited, in accordance with accepted academic practice. No use, distribution or reproduction is permitted which does not comply with these terms. 